debate

$\mathrm{PH} 101$

a debate Hacia una nueva institucionalidad cultural. Modelos emergentes de gestión...

| coordina Jesús Carrillo Castillo

\title{
Cultura, Estado, diálogo e institucionalidad
}

\author{
Ramiro Ernesto Villamagua Vergara, Alexandra Delgado, Felipe Ogaz Oviedo, Patricio Carvajal Guarderas, Sara Oviedo Fierro \\ | Colectivo de Gestión Cultural "Diabluma"
}

URL de la contribución <www.iaph.es/revistaph/index.php/revistaph/article/view/4759>

En primera instancia, se requiere contextualizar brevemente esa institucionalidad cultural, que para el caso de Ecuador, ha pasado de ser una especie de fantasma en el modelo neoliberal, a un planteamiento más eficiente bajo el modelo neo-desarrollista, lo que Segato (2007) denomina la "producción de identidades", con el fin de sacarle partido a la diversidad. La constitución vigente (2008) plantea un "Estado plurinacional e intercultural", pero la estructura estatal sigue siendo "nacional" y por tanto, la gestión cultural que puede dotar esta institucionalidad no deja de ser deficiente y subsidiaria, homogenizante y aún sesgada, misma que a nivel de Gobiernos Autónomos Descentralizados (GAD) suele ser vista como un aditivo para la imagen política, por lo cual, se acostumbra a instrumentalizar y folklorizar las manifestaciones culturales con fines del todo espurios.

Es así cómo a primera vista es indudable la necesidad de "descolonizar" la mirada que se tiene en torno a las manifestaciones culturales, las mismas que si son detentadas por "los otros" son asumidas como elementos de exotismo, que pueden ser comercializadas a los visitantes, en el caso del sector turístico. En cambio, que si la manifestación responde al gran segmento de la creatividad, el manejo de las bolsas de becas y auspicios suele también ser distribuido desde el "compadrazgo", por los vicios propios de una institucionalidad débil, a menudo no del todo capacitada, robotizada, preocupada más por las evidencias del trabajo que en el fin mismo de su gestión.

Esto indica que a corto plazo, sin una especie de cambio cultural urgente, es muy difícil generar dinámicas más sustentables desde la institucionalidad. Sin embargo, visto está el concepto de gobernanza cultural, que en nuestro caso, asumido desde una óptica general, no es otra cosa que el sector "cultura en el quinto poder" o "poder ciudadano". En ese sentido, el cambio institucional puede ser factible en la medida en que se logre al menos concretar redes de cooperación socio-institucionales, espacio desde el cual se puede liderar cierta transformación e incidir en las instituciones, e incluso sobre empresas.

La gestión de modelos sostenibles está atravesada por varios ejes que convergen en cada nodo temático en el que se pretenda incidir. Sean los "enfoques de igualdad" contemplados en la Constitución del Ecuador como los elementos inscritos en los tratados de derechos humanos o los derechos de la naturaleza, que requieren de una visión múltiple que no excluya la rentabilidad social y económica del todo y sus partes. Las instituciones culturales requieren aceptar que la co-construcción de la política pública así como las acciones concomitantes, requieren de una descentralización y concentración de la gestión, así como una fuerte capacidad de medir el impacto de las decisiones.

Por otro lado, hay que replantearse el papel de los museos y otros espacios de la memoria y/o creatividad: precisan convertirse en puntos de referencia para la dinámica de nuevas plataformas de interacción cultural, tanto a nivel micro como de aquellas actividades de alcance masivo. Dicho de otra forma, estas instituciones deberían convertirse en una suerte de ejes programáticos del quehacer cultural, alrededor de ellos organizar las actividades comunitarias culturales.

De ahí que resultaría interesante el descentrar la atención de la gestión cultural desde el Estado y las instituciones hacia lógicas venidas de la periferia; esto permitirá una suerte de deconstrucción de los sistemas de poder imbuidos en la dinámica de la cultura hegemónica. De ahí que la misma lógica del dialogo derive en sistemas 
a debate Hacia una nueva institucionalidad cultural. Modelos emergentes de gestión...

| coordina Jesús Carrillo Castillo

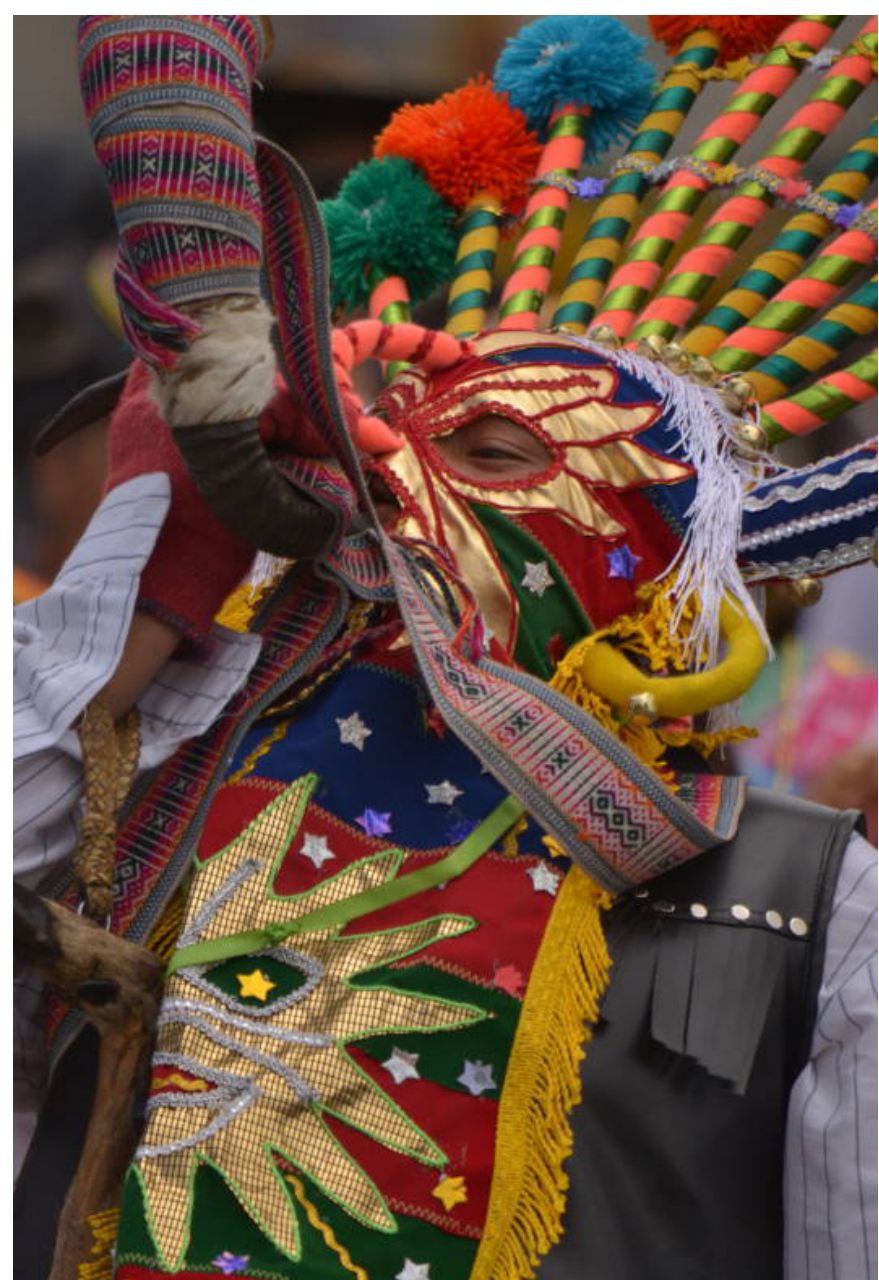

Diabluma, máscara de doble rostro considerada guía y consejera de la comunidad | foto Diego Tirira

de representación simbólica contextualizadas en las realidades actuales y, es deseable, contextualizadas en las tramas históricas de los pueblos.

En este contexto resulta vital reflexionar si es deseable la agilidad, que está ligada a términos de eficiencia y eficacia propios de un modelo económico que se encuentra también en crisis, o resulta necesario pensar en la adecuación a las demandas sociales. El hecho de que las instituciones respondan a las demandas sociales de manera adecuada, puede ser lo deseable y, exige superar la vertiginosa mirada productivista. En ese sentido, podría expandirse la institucionalidad a sistemas de diálogo en los que las acciones burocráticas sean sólo una herramienta de la gestión social. Ahí se dejarán de medir indicadores de gestión para pasar a modelos de impacto en los que se priorice lo que pasa realmente con la sociedad a partir de la implementación de una política pública, además en un marco de transparencia en el que los actos de gestión de lo público partan de la contraloría social y de la corresponsabilidad ciudadanía/Estado.

Finalmente, cabe referirse al tiempo que nos contiene, y que tiene por estigma el fenómeno de la pandemia global y de la crisis sanitaria. Parece inevitable la transformación comunicacional y la total expansión del espacio virtual, que para el caso de Ecuador, nuevamente, es un factor de desigualdad, ya que la accesibilidad a Internet no es universal y aún está lejos de serlo, por lo cual cabe asumir que si bien, por un lado, la virtualidad y la visualidad, entendida ésta como la preponderancia de lo visual, sirven para la difusión de gran manera y es posible adaptar esta modalidad a sistemas de transmisión-adquisión de cultura formales, esto es mucho más complejo para calidades como la del conocimiento tácito, situación a tener muy en cuenta por parte de las instituciones de la memoria.

\section{BIBLIOGRAFÍA}

- SEgATO, R. L. (2007) La Nación y sus Otros: raza, etnicidad y diversidad religiosa en tiempos de Políticas de la Identidad. Buenos Aires: Prometeo Libros, 2007 